\title{
An analysis of temporomandibular joint vibration about the balanc- ing side occlusal contacts and temporomandibular joint noises
}

\author{
Se-Jin Joo ${ }^{1}$, Dong-Wan Kang ${ }^{2,3}$, and Gyeong-Je Lee ${ }^{2,3 *}$ \\ ${ }^{1}$ Apple tree Dental Clinic, Pyeongtaek 17936, Republic of Korea \\ ${ }^{2}$ Department of Prosthodontics, School of Dentistry, Chosun University, Gwangju 61452, Republic of Korea \\ ${ }^{3}$ Oral Biology Research Institute, Chosun University, Gwangju 61452, Republic of Korea
}

(Received Jan 17, 2018; Revised version received [1] Jan 29, 2018 [2] Feb 8, 2018; Accepted Feb 12, 2018)

\begin{abstract}
The purpose of this study is to investigate the effect of balancing side occlusal contacts on temporomandibular joints (TMJ) through sonography. In this study, 100 adults with no symptoms of temporomandibular disorder (TMD) such as pain or opening disorder but with the possibility of clicking sounds were investigated. Subjects were checked for occlusal interferences with articulating paper, and the presence of clicking sounds with TMJ palpation and stethoscopy. Subsequently, they were classified into four groups according to their status of occlusal interferences or clicking sounds for each category. The joint vibration of the subjects was recorded using joint vibration analysis (JVA). JVA indexes (total integral, integral $300 \mathrm{~Hz}$, peak amplitude, peak frequency, $>300 /<300$ ratio, med. frequency, max. opening) were measured and compared. All JVA indexes showed no statistically significant difference between the groups. Only JVA index of $>300 /<300$ ratio, med. frequency showed a statistically significant difference in the group with both interference and clicking sound. If there are balancing side interferences and clicking sounds at the same time, a larger $>300 /<300$ ratio, med. frequency showed that the interferences and the TMJ clicking sounds were chronic and affected the TMJ vibration.
\end{abstract}

KEY WORDS: Balancing side occlusal contact, Temporomandibular joints (TMJ) clicking sound, Joint vibration analysis (JVA)

\section{서 론}

측두하악장애(Temporomandibular disorder; TMD)는 양 측 턱관절과 근육, 여기에 분포하는 혈관 및 신경에 나타 날 수 있는 모든 문제로 정의할 수 있으며, 저작근 및 악 관절의 통증, 악관절 잡음, 하악운동의 제한 등의 증상을 보인다. 측두하악장애를 쉽게 일으킬 수 있는 기여요인으 로는 외상, 정서적 스트레스, 심부통증의 유입, 이상기능 활동, 교합 이상이 있다[1].

이중 교합이 측두하악장애의 원인이라는 것에는 여전히 많은 이견이 존재한다. Molin 등[2]은 측두하악장애의 유 무와 상관없이 교합장애의 발현 빈도에서 큰 차이가 없다 고 한 반면 Pullinger 등[3]은 근골격적 안정위와 치아의 최대 교두간 접촉위 사이의 불일치가 관절낭 내장증의 발

*Corresponding author: Gyeong-Je Lee

Department of Prosthodontics, School of Dentistry, Chosun University, 303 Pilmun-daero, Dong-gu, Gwangju 61452, Republic of Korea Tel.: +82-62-220-3827, Fax: +82-62-220-3827

E-mail:1kj1998@chosun.ac.kr
생가능성을 증가시킨다고 보고하였고, Williamson [4]은 측방운동시의 양측성 교합 접촉을 보이는 경우 해당 운동 시 좌우측 측두근과 교근 네 개의 근육을 모두 활성화한 다고 하였다. Solberg 등[5]은 이러한 두 가지 의견을 절충 하였는데, 교합 이상이 다른 요인들과 복합적으로 작용 시 악영향을 미친다고 하였다.

측두하악장애의 흔한 증상 중 하나인 악관절 잡음은 clicking, popping, crepitus로 분류되며, 이중 clicking sound는 동통이나 기능 이상의 증상을 동반하지 않을 경우 병적으 로 간주하지 않는다[6,7]. 그러나 Widmalm 등[8]에 의하면 악관절 잡음은 어린 나이에서부터 발생하고 측두하악장애 의 초기 증상일 가능성이 있으며 악관절잡음이 존재하는 경우 측두하악장애의 임상적 발현 빈도가 높을 수 있다고 보고하였다.

clicking sound을 포함한 악관절 잡음을 측정하는 방법 에 있어 촉진 및 청진을 이용할 수 있으나 이는 측두하악 장애가 심하게 진행된 경우를 제외하고 정확도가 낮은 방 법으로 악관절 잡음에 의한 진동이 아닌 조직의 진동을 악 관절 잡음으로 오인할 가능성이 존재한다[9]. 이러한 임상 적 한계를 극복하기 위해 악관절 잡음을 측정하는 장치가 

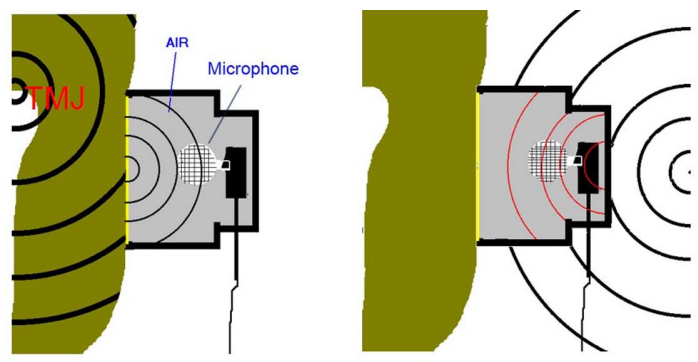

(A)

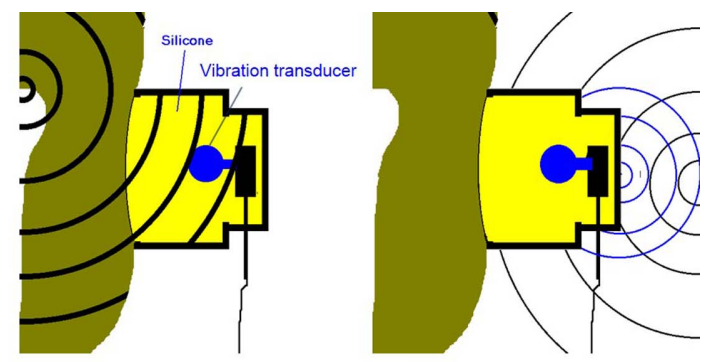

(B)

Fig. 1. Sensor design (A) Sonography Sensor Design. When a vibration occurs in the TMJ, it must be strong enough to create a pressure wave that will transmit to the air in the sensor and make it to the microphone.

개발되었는데 음파촬영술(sonography)과 전자진동술 (electrovibratography)이 이에 해당한다. 음파촬영술은 악 관절 잡음이 발생할 때 생기는 악관절 자체의 진동을 측 정하는 것이 아니며, 악관절의 진동으로 인해 일어나는 조 직의 진동을 측정한다. 반면에 전자진동술은 악관절 잡음 에 의해 발생하는 악관절 자체의 진동을 측정하고 더불어 주 변의 소음을 차단하여 보다 정확한 측정이 가능하다. 전자진 동술의 원리를 이용한 장치로는 대표적으로 Joint Vibration Analysis (JVA) (BioResearch. Inc., Milwaukee, Wisconsin, $\mathrm{USA}$ )가 있으며 이러한 장치들과 음파촬영술의 차이는 센 서의 디자인 차이로 발생한다. 음파촬영술에 사용되는 센 서는 센서 안에 마이크로폰이 내장되어 있는며 마이크로 폰의 빈 공간이 공기로 채워져 있는 반면 전자진동술의 센 서는 빈 공간이 실리콘으로 채워져 있어 악관절의 진동을 그대로 전달하게 된다[10](Fig. 1).

측두하악장애와 교합과의 관계에 관한 기존의 많은 연 구들은 임상적 증상, 저작근의 활성 및 교합력 등을 측정 하는 방법을 이용하였으나 악관절 잡음을 이용한 연구는 부족한 실정이다. 더불어 이미 심한 측두하악장애를 갖고 있는 환자가 아닌 잠재적인 환자군에서의 교합과의 관계 를 입증한 연구 또한 부족한 실태이다. 앞서 Widmalm 등 [8]이 언급한 것과 같이 clicking sound는 측두하악장애의 발현 빈도를 높일 수 있다고 하였다. 이는 교합과 clicking sound의 관계를 파악하는 것이, clicking sound를 갖고 있 는 경우 측두하악장애로 진행하는데 있어 하나의 예방법 으로서 교합 조정이 가능할지 판단케 할 것이다. 그래서 본 연구의 목적은 전자진동술의 하나인 JVA를 이용하여 측방운동 시의 균형측 간섭과 악관절 잡음의 관계를 알아 보는 것이다.

\section{재료 및 방법}

\section{연구 대상 및 분류}

20-30대(평균 28.5세)의 조선대학교 치과병원에 내원한
Table 1. Classification of each group

\begin{tabular}{|c|c|c|c|c|}
\hline Classification & $\begin{array}{l}\text { Balancing side } \\
\text { interference }\end{array}$ & $\begin{array}{l}\text { Clicking } \\
\text { sound }\end{array}$ & $\begin{array}{l}\text { Number of } \\
\text { subjects }\end{array}$ & $\begin{array}{c}\text { Total number } \\
\text { of subjects }\end{array}$ \\
\hline Group 1 & No & No & 24 & \multirow{4}{*}{90} \\
\hline Group 2 & No & Yes & 17 & \\
\hline Group 3 & Yes & No & 32 & \\
\hline Group 4 & Yes & Yes & 17 & \\
\hline
\end{tabular}

환자 및 모집공고에 지원한 조선대학교 치의학전문대학원 학생 중 측두하악장애 병력과 현재 동통 및 운동 제한과 같은 측두하악장애를 보이지 않고, 정상 개구량을 보이며, 3 대구치를 제외한 상실치가 없는 유치악 환자 100 명을 대 상으로 하였다. 류마티스 관절염과 같은 만성 전신 질환이 있는 경우, JVA의 개폐구 운동을 잘 따라하지 못하는 경 우 대상자에서 제외하였다.

실험 진행에 앞서 조선대학교 치과병원 임상시험 심사 위원회의 심의(CUDHIRB 1608 036)를 거쳐 진행하였다.

대상자들은 측방운동시의 좌우 구치부의 균형측 간섭 유무와 환자의 문진과 촉진에 의해 측정되는 측두하악관 절의 clicking sound의 유무에 따라 그룹으로 분류하였다. 총 100 명의 대상자 중 측방운동시 구치부 균형측 교합간 섭이 편측에 존재하는 경우(10명)는 대상자에서 제외하였 다(Table 1).

\section{연구 방법}

\section{측방운동시 간섭 유무 측정}

측방운동시의 균형측 간섭 유무를 판단하기 위해 측정 에 앞서 측방운동 반복훈련을 시행하였다. 상악 중철치를 기준으로 최대교두감합위에서 좌우로 $3 \mathrm{~mm}$ 까지 운동시켰 으며 T-Scan II system (T-Scan system, TekScan Inc., Boston, $\mathrm{MA}, \mathrm{USA}$ )을 이용하여 측방운동시의 구치부 간섭 유무를 판단하였다. T-Scan sensor 두께로 인한 측정 오차를 줄이 기 위해 교합지(AccuFilm II, Parkell Inc., Edgewood, NY, 


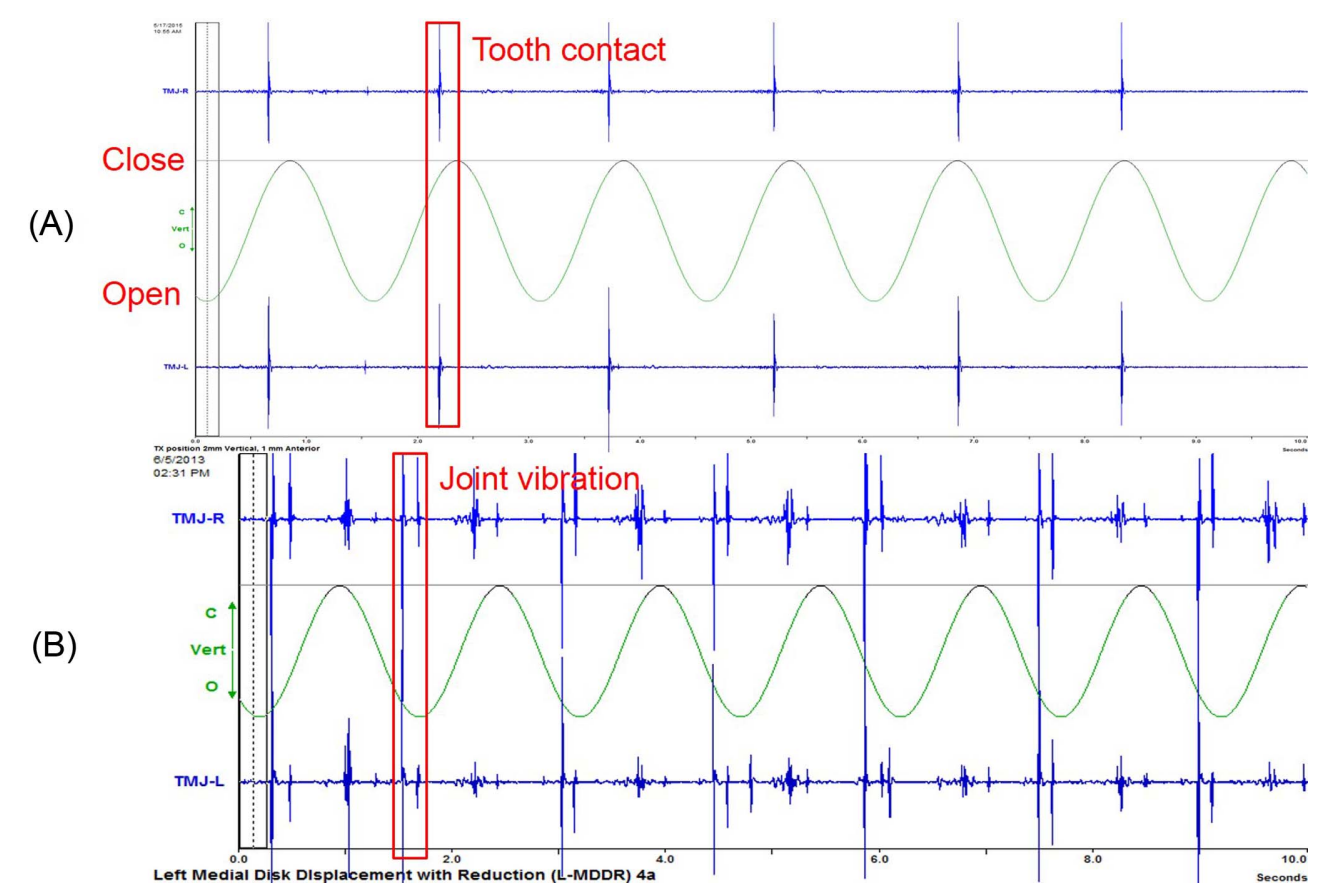

Fig. 2. Sample Joint Vibration. Middle line of JVA is the metronome (A) normal JVA Screening Trace (B) abnormal JVA Screening Trace

USA)를 사용하여 검증하였다. T-scan 측정시에 간섭이 존재 한다고 측정되었으나 측방운동시 구치부에서 교합지가 물리 지 않는 경우 간섭이 존재하지 않는 것으로 간주하였다.

\section{악관절 잡음의 측정}

$\mathrm{JVA}$ 는 최대 개구시와 폐구시에 발생하는 측두하악관절의 진동을 센서를 통해 측정하고 측정된 진동의 파장을 증폭하 여 컴퓨터상의 프로그램(BioPAKTM, BioResearch. Inc., Milwaukee, Wisconsin, USA)으로 수치가 구현한다[10].

실험은 다른 소리에 영향을 받지 않는 실험실에서 진행 하였고, 피실험자들을 편안한 상태로 의자에 앉히고 좌우 측 과두 상방에 센서를 위치시켜 JVA 측정을 진행하였다. 피 실험자들의 최대개구량을 측정하여 프로그램상에 입력하 고 악관절 잡음의 측정에 앞서 개폐구 운동의 재현성을 위 해 60 초간 반복적인 개폐구 운동을 연습시켰다. 폐구시에 는 치아의 접촉음이 확실히 발생하도록 연습시켰다. 일정 한 개폐구 운동을 위해 컴퓨터 모니터상의 개폐구 운동 동 영상 및 메트로놈 소리에 맞춰 1.5 초당 1 회 운동의 빈도로 진행하였다. 60 초간의 연습 후 개폐구 운동을 중단하지 않 은 채로 이어서 바로 악관절 잡음을 측정하였다. 각각의 피실험자들은 적어도 6 회 이상의 개폐구 운동을 시행하여 악관절 잡음을 측정하였다.

\section{JVA 분석}

개폐구시에 발생하는 잡음은 진동의 진폭으로 표현된다. 폐구시에 발생하는 치아 접촉에 의한 진동을 제외하고 운

\begin{tabular}{|c|c|c|c|c|c|c|}
\hline \multicolumn{7}{|l|}{ 䀠 JVA Summary } \\
\hline Help & \multicolumn{2}{|c|}{ Average } & \multicolumn{2}{|c|}{ Window 1} & \multicolumn{2}{|c|}{ Window 2} \\
\hline Narrative & Left & Right & Left & Right & Left & Right \\
\hline Total Integral & 146.7 & $106 \%$ & 132.8 & $89 \%$ & 129.5 & $94 \%$ \\
\hline Max. Opening & & 50 & & & & \\
\hline Integral $<300 \mathrm{~Hz}$ & 115.7 & -- & 107.0 & 103.9 & 105.9 & 103.5 \\
\hline Integral $>300 \mathrm{~Hz}$ & 31.0 & -- & 25.8 & 14.0 & 23.7 & 18.4 \\
\hline$>300 /<300$ Ratio & 0.27 & -- & 0.24 & 0.13 & 0.22 & 0.18 \\
\hline Peak Amplitude & 6.0 & -- & 5.7 & 6.1 & 5.9 & 6.3 \\
\hline Peak Frequency & 68 & 91 & 72 & 87 & 76 & 37 \\
\hline Med. Frequency & 169 & 126 & 162 & 126 & 158 & 126 \\
\hline Est. Velocity & 86.3 & --- & 66.3 & 65.0 & 90.6 & 86.2 \\
\hline Distance to co & 38.1 & -- & 43.9 & 44.2 & 37.1 & 37.5 \\
\hline Lat. Deflection & & $1 \mathrm{~L}$ & & & & \\
\hline
\end{tabular}

Fig. 3. Parameters were calculated within the BioPAK program.

동 중 발생하는 가장 큰 진폭을 보이는 지점을 선택하였 다(Fig. 2).

각각의 수치는 좌/우 진동 중 mirror image와 $>300 /<300$ ratio를 고려하여 원인 관절로 감별되는 쪽을 선택하였다[11].

개폐구 운동의 4-6회째 구간에서 가장 큰 진폭을 보이는 3 지점을 선택하였고 이 3 지점에서의 평균을 이용하여 다 음 항목들을 측정하였다[12](Fig. 3).

- Total integral : 악관절 잡음에 의해 발생하는 진동의 총에너지로 0 에서 $500 \mathrm{~Hz}$ 사이의 에너지의 총량을 의 미한다.

- Integral $<300 \mathrm{~Hz}: 300 \mathrm{~Hz}$ 이하에 해당하는 에너지 총 량으로 이 영역은 디스크의 변위 및 정복, 관절의 과 
운동 영향을 받는다.

- Integral $>300 \mathrm{~Hz}: 300 \mathrm{~Hz}$ 이상에 해당하는 에너지 총 량으로 관절의 파괴적인 변화와 연관된다.

- >300/<300 ratio : 고주파수 영역 에너지에 대한 저주 파수 영역 에너지의 비율로 관절의 파괴적인 변화와 연관된다.

- Peak amplitude : 진폭이 가장 클 때의 진폭 값을 의 미한다.

- Peak frequency : 가장 높은 진폭을 가질 때의 주파수 값 을 의미하며 관절 및 디스크 변위의 만성화와 연관된다.

\section{통계학적 분석}

SPSS Ver. 20.0 (SPSS Inc, Chicago, IL, USA) 프로그램 을 이용하여 통계처리 하였으며, 각 그룹간의 측방운동시 에 발생하는 구치부 교합간섭과 clicking souund의 연관정 도를 확인하기 위해 Kruskall-Wallis test $(\mathrm{P}<0.05)$ 와 t-test $(\mathrm{P}<0.05)$ 를 사용하였다.

\section{결 과}

악관절 잡음에 의해 발생하는 진동의 총에너지를 의미
하는 total integral은 모든 그룹에서 $20 \mathrm{~Hz}$ 이하의 적은 에 너지 총량을 보였으며, 대부분의 피실험자에서 $300 \mathrm{~Hz}$ 이 하에 집중된 에너지 분포를 보였다. $>300 /<300$ ratio는 모 두 평균 0.2 이하의 낮은 값을 보였다(Table 2).

각각의 그룹 간 비교 시 모든 항목에서 통계적으로 유 의할만한 차이를 보이지 않았다(Table 3). 간섭 유무에 따 른 항목간 비교를 위해 그룹 1,2 대 그룹 3, 4 간 비교 시 통계적으로 유의할만한 차이를 보이지 않았고, (Table 4) clicking sound에 따른 항목간 비교를 위해 그룹 1, 3 대 그 룹 2, 4 간 비교 시에도 통계적으로 유의할만한 차이를 보 이지 않았다. 다만 med. frequency는 통계적으로 유의할만 한 수준은 아니나 clicking sound가 존재하는 경우 다소 크 게 나타나는 경향을 보였다(Table 5).

\section{고 찰}

측방운동시의 교합간섭을 포함한 교합접촉양상에 대한 많은 문헌들이 존재하는데, Ogawa 등[13]은 측방운동시 작업측의 견치에서 가장 많은 교합 접촉 빈도를 보인다고 하였고 Song 등[14]의 연구도 이와 비슷한 결과를 보였다. 한 국인을 대상으로 한 Song 등의 실험은, 측방운동시 작업

Table 2. Mean (SD) vibration values of each group

\begin{tabular}{lcccc}
\hline & Group 1 & Group 2 & Group 3 & Group 4 \\
\hline Total integral & $12.28 \pm 4.33$ & $17.83 \pm 12.30$ & $18.96 \pm 15.08$ & $19.48 \pm 18.29$ \\
Integral $<300$ & $10.99 \pm 3.93$ & $16.40 \pm 11.02$ & $17.29 \pm 13.66$ & $17.16 \pm 16.05$ \\
Integral $>300$ & $1.33 \pm 1.06$ & $1.84 \pm 1.56$ & $1.78 \pm 2.03$ & $2.28 \pm 2.58$ \\
$>300 /<300$ ratio & $0.16 \pm 0.09$ & $0.19 \pm 0.08$ & $0.16 \pm 0.10$ & $0.19 \pm 0.09$ \\
Peak amplitude & $1.90 \pm 1.03$ & $2.05 \pm 1.13$ & $2.38 \pm 1.74$ & $2.29 \pm 1.99$ \\
Peak frequency & $43.58 \pm 15.09$ & $54.59 \pm 28.71$ & $48.56 \pm 19.77$ & $45.18 \pm 14.51$ \\
Med. frequency & $84.29 \pm 36.43$ & $99.18 \pm 30.88$ & $89.47 \pm 37.35$ & $105.41 \pm 39.34$ \\
Max. opening & $52.63 \pm 5.42$ & $53.12 \pm 5.01$ & $51.20 \pm 4.74$ & $52.50 \pm 7.71$ \\
\hline
\end{tabular}

Table 3. Correlation between groups on vibration values

\begin{tabular}{ccccc}
\hline & Total integral & Integral $<300$ & Integral $>300$ & $>300 /<300$ ratio \\
\hline p-value & 0.507 & 0.427 & 0.325 & 0.411 \\
\hline p-value & Peak Amplitude & Peak frequency & Med. frequency & Max. opening \\
\hline
\end{tabular}

a) Statistically significant difference $(\mathrm{P}<0.05)$ (Kruskall-Wallis test).

Table 4. Correlation between groups (group 1, 3 vs group 2, 4) according to clicking sound

\begin{tabular}{ccccc}
\hline & Total integral & Integral $<300$ & Integral $>300$ & $>300 /<300$ ratio \\
\hline p-value & 0.093 & 0.100 & 0.283 & 0.922 \\
\hline p-value & Peak Amplitude & Peak frequency & Med. frequency & Max. opening \\
\hline
\end{tabular}

a) Statistically significant difference $(\mathrm{P}<0.05)(\mathrm{t}$-test). 
Table 5. Correlation between groups (group 1, 2 vs group 3, 4) according to occlusal interference

\begin{tabular}{ccccc}
\hline & Total integral & Integral $<300$ & Integral $>300$ & $>300 /<300$ ratio \\
\hline p-value & 0.383 & 0.408 & 0.239 & 0.186 \\
\hline p-value & Peak Amplitude & Peak frequency & Med. frequency & Max. opening \\
\hline
\end{tabular}

a) Statistically significant difference $(\mathrm{P}<0.05)(\mathrm{t}$-test).

측에서 견치 유도보다 군기능 유도가 더 큰 빈도를 보였 으나 개개의 치아 접촉 빈도는 견치에서 $34 \%$ 로 가장 높은 접촉 빈도를 보이고 구치부로 갈수록 낮은 접촉빈도를 보 인다고 하였다. 피실험자의 $44.8 \%$ 에서 측방운동시 균형측 에서의 교합 접촉이 관찰되었으며, 작업측 및 균형측 양쪽 에서 교합접촉이 나타나는 경우는 $40.2 \%$, 오직 균형측에서 만 교합접촉이 관찰되는 경우는 $4.6 \%$ 의 비율을 보였고 균 형측에서의 치아 접촉은 주로 제 2 대구치에서 관찰되었다. 본 실험에서 균형측에서의 교합 접촉 빈도는 약 $45 \%$ 로 Song 등[14]의 실험과 유사한 결과를 나타내었다. 다른 문 헌들을 살펴보면 De Laat 등[15]은 61\%에서 Sadowsky 등 [16]은 88-91\%에서 Agerberg 등[17]은 23-25\%에서 측방운 동시 균형측의 교합접촉을 보인다고 하였다. 이러한 논문 들은 연구대상이나 연구방법에 따라 차이를 보이나 상당수 의 사람들에서 균형측에서의 교합 접촉이 존재한다는 것을 의미한다. 균형측에서의 교합간섭이 측두하악관절에 부정
적인 영향을 미친다는 것에는 많은 이견이 존재하나, Mohlin 등 [18]은 측두하악장애를 보이는 환자들에서 더 많 은 균형측 교합간섭이 존재한다고 하였다. 본 실험에서는 한국인의 교합에서 발현 빈도가 높으며 측두하악장애를 일 으킬 가능성 높은 경우를 대상으로 진행하고자 하였으며 실제로 측방운동시 작업측과 더불어 균형측에서도 교합접 촉이 존재하는 피실험자를 대상으로 진행하였다.

Ishigaki 등[19]은 측두하악장애가 있는 경우 악관절 잡 음이 정상적인 범주의 진동을 보일지라도 정상 범주보다 큰 진동을 보인다고 하였다. 또한 total integral을 이용한 진단시 민감도는 $75 \%$, 특이도는 $77 \%$ 라고 하였으며[20] 특히 초기 정복성 관절원판 변위 시 민감도는 $96.6 \%$, 후 기 정복성 관절원판 변위시 민감도는 $91.8 \%$ 의 높은 민감 도를 보인다고 하였다[21]. 본 연구의 피실험자들은 일부 몇몇을 제외하고 대부분 $20 \mathrm{~Hz}$ 이하의 낮은 total integral 을 보였고 일부에서만 $80 \mathrm{~Hz}$ 이상의 수치를 보였다. Huang

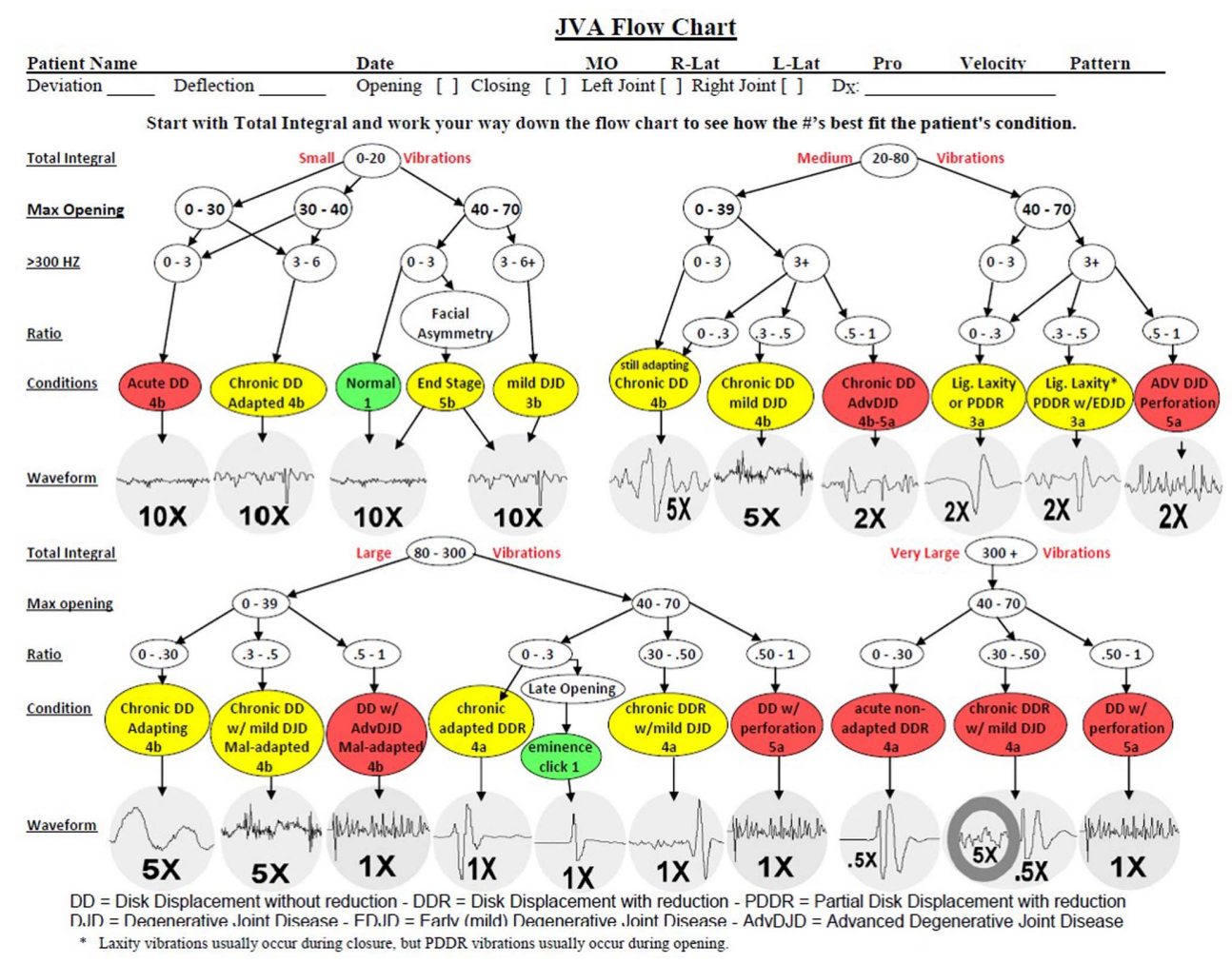

Fig. 4. JVA flow chart provided by BioResearch. Inc. 
등[22]은 total integral에 있어 $20 \mathrm{~Hz}$ 를 기준으로 정상과 정복성 관절원판 변위로 구분시 그 민감도는 $85.7 \%$ 이며 특이도는 $84.6 \%$ 라고 하였다. 이러한 결과는 BioResearch. Inc.에서 제공하는 JVA flow chart에서도 확인할 수 있으 며[23] 정상의 경우 대개 $20 \mathrm{~Hz}$ 의 이하의 total integral을 보인다(Fig. 4). 피실험자들을 flow chart를 이용하여 잠정 진단할 경우 모두 정상 범주에 해당했으며 $80 \mathrm{~Hz}$ 의 이상의 total integral을 보이는 경우도 단순 eminence click에 의한 것 으로 진단되었다.

JVA 데이터를 분석하기 위해 개폐구시에 발생하는 잡음 의 진폭 중 폐구시에 발생하는 치아 접촉에 의한 진동을 제외하고 운동 중 발생하는 가장 큰 진폭을 보이는 지점 을 선택하였다. Radke 등[24]에 의하면 대개 개폐구 운동 의 4-6회째 구간에서 가장 큰 진동을 보인다고 하였으며 이를 토대로 4-6회째 구간에서 가장 큰 진폭을 보이는 3 지점을 선택하였다.

Radke 등[25]은 한쪽 관절에서 발생한 진동은 반대쪽 관 절에 전달되며 반대쪽 관절에서는 진동이 발생하는 관절 에서의 파장과 반대로 나타는 mirror image가 나타난다고 하였다(Fig. 5). Widmalm 등[26]은 진동의 전달이 하악골 을 통해 전달되고 반대쪽 관절에서는 약간의 시간차를 두 고 진동이 나타나며 연령이나 골밀도, 골질에 따라 전달되 는 비율은 다르게 나타난다고 한 반면 Radke 등[25]은 관 절원판의 변위의 의한 하악골의 튕김 현상에 의한 것으로 방향에 따라서도 진동이 전달되는 정도가 달라지며 관절 원판이 전후방이 아닌 좌우 측방변위 시에 더 큰 전달을 보인다고 하였다. 본 연구에서는 이러한 원리를 기반으로 mirror image를 참고하여 진동을 일으키는 원인 관절을 결 정하였으며 mirror image가 명확하지 않는 경우 $>300 /<300$ ratio 수치를 참고하였다.

Jung 등[11]은 명확한 mirror image를 보이지 않는 경우 진동이 전달된 관절에서 10 이하의 낮은 total integral을 보
이며 진동이 발생한 관절에 비해 더 큰 >300/<300 ratio 값 을 보인다고 하였다. 이는 $300 \mathrm{~Hz}$ 이상의 에너지를 갖는 진동의 경우 $300 \mathrm{~Hz}$ 이하의 에너지를 갖는 진동에 비해 골전도가 더 잘 일어나며 이로 인해 $300 \mathrm{~Hz}$ 이상의 진동 이 원인관절의 반대측으로 전달되기 때문이다.

$\mathrm{JVA}$ 는 $500 \mathrm{~Hz}$ 이하의 에너지를 측정하며 이를 $300 \mathrm{~Hz}$ 를 기준으로 에너지 총량을 산출한다. 높은 integral $<300 \mathrm{~Hz}$ 값 은 관절 원판의 과운동을 의미한다. 그래서 일반적으로 인 대가 더 느슨하며 관절낭이 더 큰 여성에서 남성보다 큰 수 치를 보인다[12]. 이에 반해 높은 integral $>300 \mathrm{~Hz}$ 값은 측두 하악관절의 퇴행성 변화를 의미한다[25]. Ishigaki 등[19]에 의하면 정상군과 측두하악장애 병력이 있는 실험군간의 비 교시 integral $<300 \mathrm{~Hz}$ 값은 차이를 보이지 않으나 병력이 있 는 군에서 정상군에 비해 더 높은 Integral $>300 \mathrm{~Hz}$ 값을 보 인다고 하였고 또 다른 연구[27]에서는 측두하악관절의 퇴 행성 변화시 350-450 Hz의 높은 에너지를 보이는 진동이 일 어난다고 하였다. Huang 등[28]에 의하면 측두하악장애가 없는 정상군에서는 $>300 /<300$ ratio 중앙값이 0.1 인 반면 정 복성 관절원판 변위가 있는 군에서는 0.58 의 높은 중앙값을 보인다고 보고하였는데 본 연구에서는 모든 그룹에서 0.2 이하의 값을 보였다. 이는 0.1 보다는 약간 큰 값을 가지나 정상그룹에서 작은 $>300 /<300$ ratio 값을 보인다는 많은 연 구들의 결과와 일치한다 $[19,27,28]$.

본 연구 결과, 측방운동시 존재하는 구치부 교합간섭은 측두하악관절의 병적인 음파 변화를 일으키지 않았으며 모든 피실험자들은 정상적인 파형을 보였다. Tsolka 등 [29]은 측두하악장애와 교합간섭이 모두 있는 환자군에서 교합간섭을 제거하였으나 측두하악장애의 증상을 현저하 게 개선시키지는 못했다고 하였으며, Rugh 등[30]에 의하 면 조기 접촉의 존재가 야간 이갈이를 증가시키지는 않았 다고 하였다. 즉 구치부의 조기 접촉이 반드시 근활성을 증가시키지는 않는다고 하였는데 이러한 결과는 앞에서

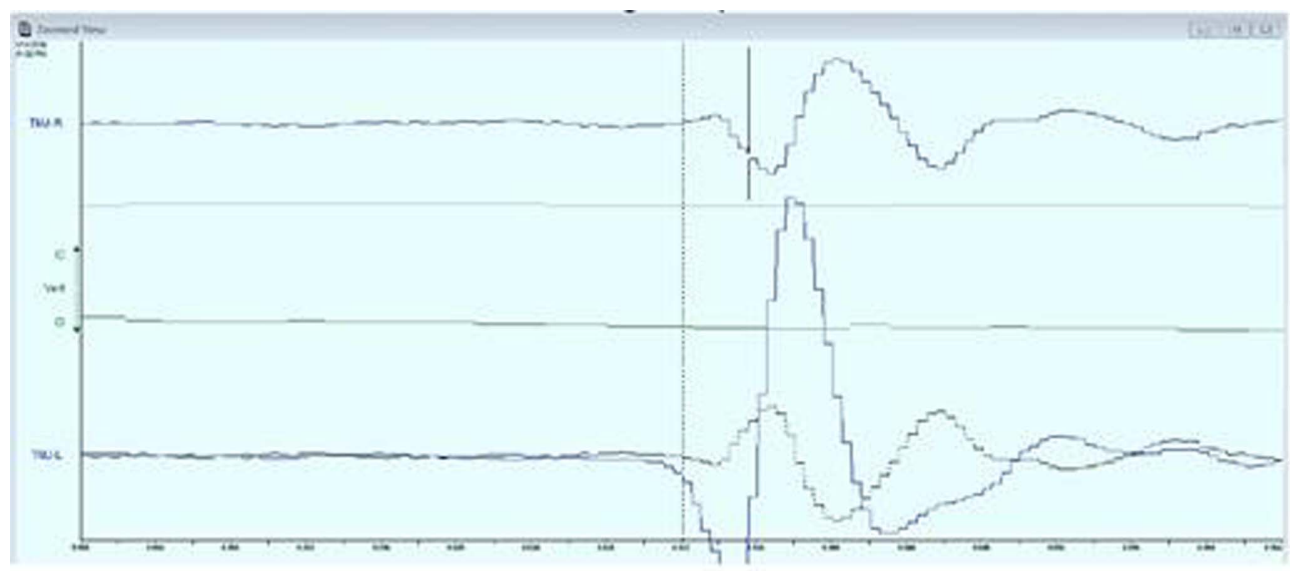

Fig. 5. Mirror image. There is transferred vibration in right side overlapped in lower waveform of left side vibration. 
언급한 Widmalm 등[8]의 연구와는 반대되는 결과를 보인 다. Seligman 등[31]도 비슷한 결과를 보였는데 교합간섭 의 발현 빈도는 측두하악장애 환자와 정상인간에 차이를 보이지 않으며 측두하악장애 증상과 밀접한 관계를 보이 지 않는다고 하였다. 위에서 언급한 것과 같이 많은 연구 에서 교합간섭과 측두하악장애가 관련이 없음을 보이며 본 연구의 결과와 일치한다. 실험의 결과에 의하면 교합간 섭이 clicking sound와 연관이 없으며, 교합간섭이 존재할 경우 교합 조정이 clicking sound의 치료 혹은 하나의 예 방법이 될 수 없음을 간접적으로 보여준다. 본 실험은 단 순 clicking sound와 교합간섭간의 관계를 규명하였으며 교합간섭과 측두하악장애의 관계에 있어 더 많은 연구가 필요할 것으로 사료된다.

Randolph 등[6]은 110 명의 측두하악장애를 환자를 대상 으로 진행한 장기간 연구에서 단순 clicking sound가 존재 한 경우 단 7\%만이 1-7.5년 후 TMJ의 병적인 상태로 진 행하였고, Widmalm 등[32]은 clicking sound의 존재 유무 가 $\mathrm{TMD}$ 의 감별 기준이 되지는 않는다고 하였으며, Kononen 등[33]에 의하면 clicking sound의 발현 빈도는 연령이 증 가함에 따라 증가하나 locking으로의 진행은 보이지 않는 다고 하였다. 이러한 연구 결과와 비슷하게 본 연구에서 clicking sound가 측두하악관절의 병적인 음파 변화를 야 기하지 않았다.

본 연구에서는 피실험자의 크기가 크지 않고 성별이나 나이를 고려하지 않은 점, 교합간섭이나 clicking sound가 존재한 경우 시간의 경과에 따른 측두하악관절의 음파 변 화를 고려하지 않는 등의 한계점이 존재하는 바 이에 관 한 추가적인 연구가 필요할 것으로 사료된다.

\section{감사의 글}

This study was conducted with the research grant of Chosun University Dental Hospital in 2016.

\section{Conflict of Interest}

The authors declare that they have no competing interests.

\section{ORCID}

$\begin{array}{ll}\text { Se-Jin Joo } & 0000-0002-1814-661 X \\ \text { Dong-Wan Kang } & 0000-0001-9455-4706 \\ \text { Gyeong-Je Lee } & 0000-0002-3545-2280\end{array}$

\section{Reference}

1. Okeson JP. Management of temporomandibular disorders and occlusion. 7th ed. Elsevier Health Sciences. 2013.

2. Molin C, Carlsson G, Friling B, Hedegaard B. Frequency of symptoms of mandibular dysfunction in young Swedish men. J Oral Rehabil 1976;3:9-18. doi: 10.1111/ j.1365-2842.1976.tb00925.x.

3. Pullinger AG, Seligman DA. The degree to which attrition characterizes differentiated patient groups of temporomandibular disorders. J Orofac Pain 1993;7:196-208.

4. Williamson EH. The role of craniomandibular dysfunction in orthodontic diagnosis and treatment planning. Dent Clin North Am 1983;27:541-560.

5. Solberg WK, Seligman DA. Temporomandibular orthopedics a new vista in orthodontics In Johnston LE (ed); New vista in orthodontics. Philadelphia Lea \& Febiger. 1985;148-183.

6. Randolph CS, Greene CS, Moretti R, Forbes D, and Perry HT. Conservative management of temporomandibular disorders : A post treatment comparison between patients from a university clinic and from private practice. Am J Ortho Dentofac Orthop 1990;98:77-82. doi: 10.1016/ 0889-5406(90)70035-B.

7. Greene CS, Laskin DM. Longterm status of TMJ clicking in patients with myofacial pain dysfunction. JADA 1998;117:461-465. doi: 10.1016/S0002-8177(88)73018-4.

8. Widmalm SE, Christiansen RL, Gunn SM. Crepitation and Clicking As Signs of TMD in Preschool Children. Cranio 1999;17:58-63. doi: 10.1080/08869634.1999.11746078.

9. Hardison JD, Okeson JP. Comparison of three clinical techniques for evaluating joint sounds. J Creaniomandib Pract 1990;8:307-311. doi: 10.1080/08869634.1990. 11678329.

10. Christensen LV. Physics and the sounds produced by the temporomandibular joints. Part I. J Oral Rehabil 1992; 19:471-483. doi: 10.1111/j.1365-2842.1992.tb01111.x.

11. Jung DU, Kang DW. Study for discriminating method of origin side vibration from non-symptomatic clicking group. J Dent Rehabil Appl Sci 2016;32:38-46. doi: 10.14368/jdras.2016.32.1.38.

12. Gupta B, Thumati P, Radke J. Temporomandibular joint vibration from totally asymptomatic subjects. Cranio 2016;34:169-175. doi: 10.1179/2151090315Y.0000000013.

13. Ogawa T, Ogimoto T, Koyano K. Pattern of occlusal contacts in lateral positions: canine protection and group function validity in classifying guidance patterns. J Prosthet Dent 1998;80:67-74. doi: 10.1016/S0022-3913(98) 70093-9.

14. Song JH, Joo SJ, Lee HS, Kang DW, Lee GJ. An occlusal contact analysis of lateral mandibular movement 
using T-Scan system. J Korean Acad Prosthodont 2015;2:128-137. doi: 10.4047/jkap.2015.53.2.128.

15. De Laat A, van Steenberghe D. Occlusal relationships and temporomandibular joint dysfunction. Part I: Epidemiologic findings. J Prosthet Dent 1985;54:835-842. doi: 10.1016/0022-3913(85)90483-4.

16. Sadowsky C, BeGole EA. Long-term status of temporomandibular joint function and functional occlusion after orthodontic treatment. Am J Orthod 1980;78:201-212. doi: 10.1016/0002-9416(80)90060-3.

17. Agerberg G, Sandstrom R. Frequency of occlusal interferences: a clinical study in teenagers and young adults. J Prosthet Dent 1988;59:212-217. doi: 10.1016/00223913(88)90017-0.

18. Mohlin B, Kopp S. A clinical study on the relationship between malocclusions, occlusal interferences and mandibular pain and dysfunction. Swed Dent J 1978;2:105112.

19. Ishigaki S, Bessette RW, Maruyama T. Vibration of the temporomandibular joints with normal radiogaphic imagings-comparison between asymptomatic volunteers and symptomatic patients. J Craniomandib Pract 1993;11:88-94. doi: 10.1080/08869634.1993.11677948.

20. Ishigaki S, Bessette RW, Maruyama T. A clinical study of temporomandibular joint (TMJ) vibrations in TMJ dysfunction patients. J Craniomandib Pract 1993;11:713. doi: 10.1080/08869634.1993.11677935.

21. Ishigaki S, Bessette RW, Maruyama T. Vibration analysis of the temporomandibular joints with meniscal displacement with and without reduction. J Craniomandib Pract 1993;11:192-201. doi: 10.1080/08869634.1993. 11677964.

22. Huang Z, Lin X, Li X. Characteristics of temporomandibular joint Vibrations in anterior disc displacement with reduction in adults. J Craniomandib Pract 2011;29:276283. doi: 10.1179/crn.2011.041.

23. Radke JC. Marking, Analyzing and Treatment Planning from JVA Data. (c) BioResearch Associates, Inc. 2013

24. Radke JC, Kull RS. Comparison of TMJ vibration frequencies under different joint conditions. Craniomandib Pract 2015;33:174-182. doi: 10.1179/2151090314Y. 0000000019.

25. Radke JC, Kull RS. Distribution of temporomandibular joint vibration transfer to the opposite side. J Craniomandib Pract 2012;30:194-200. doi: 10.1179/crn.2012.030.

26. Widmalm SE, Williams WJ, Ang BK, and Mckay DC. Localization of TMJ sounds to side. J Oral Rehabil 2002;29:911-917. doi: 10.1046/j.1365-2842.2002.00928.x.

27. Ishigaki S, Bessette RW, Maruyama T. Vibration analysis of the temporomandibular joints with degenerative joint disease. Cranio 1993;11:276-283. doi: 10.1080/ 08869634.1993.11677979.

28. Huang Z, Lin X, Li X. Characteristics of temporomandibular joint sounds in reducible anterior disc displacement of youth. Hua Xi Kou Qiang Yi Xue Za Zhi 2011;29:600-603.

29. Tsolka P, Morris RW, Preiskel HW. Occlusal adjustment therapy for craniomandibular disorders: a clinical assessment by a double-blind method. J Prosthet Dent 1992; 68:957-964. doi: 10.1016/0022-3913(92)90558-R.

30. Rugh JD, Barghi N, Drago CJ. Experimental occlusal discrepancies and nocturnal bruxism. J Prosthet Dent 1984;51:548-553. doi: 10.1016/0022-3913(84)90312-3.

31. Seligman DA, Pullinger AC. The role of intercuspal occlusal relationship in temporomandibular disorders:a review. J Craniomandib Disord Facial Oral Pain 1991;5:96106.

32. Widmalm SE, Odont D, Bae HEK, Djurdianovicet D. Inaudible temporomandibular joint vibration. Cranio 2006;24:207-212.

33. Kononen M, Waltimo A, Nystrom M. Does clicking in adolescence lead to painful temporomandibular joint locking? The lancet 1996;347:1080-1081. doi: 10.1016/ S0140-6736(96)90280-9. 